\title{
IMPROVEMENT OF WAREHOUSE PROCESSES BY IMPLEMENTATION OF LEAN SIX SIGMA IN GLOBAL SUPPLY CHAIN
}

\author{
Monika KAMIŃSKA \\ Department of Business Logistics, University of Economics in Katowice, Poland; \\ monika.m.kaminska@uekat.pl, ORCID: 0000-0003-0853-021X
}

Purpose: Nowadays businesses concentrate on the highest efficiency and lowest waste, that's why some organizations implement Lean Six Sigma as a complete package of adapted tools. This article evaluates the implementation of the Lean Six Sigma method.

Design/methodology/approach: The case study presents an approach and project scheme adjusted by Global Supply Chain Manufacturer. This paper shows the results of the LSS method implementation in the internal and 3rd Party Logistics distribution center.

Findings: This warehouse process improvement method uses tools like ECRS for process map, Cause-and-Effect Diagram, 5Why\&1How analysis, Spaghetti Diagram, Flow Process Analysis sheet, and Action Plan.

Practical implications: This article evaluates three logistics processes in two distribution centers where LSS has been applied: handling process and twice picking process. Results provide enhanced process and saving for owned DC $(0,8 \mathrm{~m} €)$ and lower rates in 3P DC (saving $2 m €)$.

Originality/value: Project was so satisfactory for the corporation that it developed global online training. The case company represents a significant source of information to gain understandings of the effects of implementing LSS in warehousing services.

Keywords: Lean Six Sigma, Six Sigma, supply chain, warehouse process, continuous improvement.

Category of the paper: Case study.

\section{Introduction}

During past decades, continuous development of cooperation and commitment between parties of the supply chain (SC) can be noticed. It is dictated by economic aspects, the market year by year demands better quality for a lower price. Partners in the SC share the knowledge and experience to deliver improved services and products. Various companies use different methodologies, approaches, and tools of available continuous improvement programs. 
It is important to choose the best set of approaches, tools, and techniques for a specific organization (Gupta, et al., 2018).

Lean Six Sigma (LSS) is an approach that combines Lean and Six Sigma tools and methodology to enhance quality, reduce process variations, and eliminate non-value added activities. The first step is to identify waste within the organization and its elimination. That reduces process variation (Salah, et al., 2011). This paper evaluates the application of LSS within the SC, as a set of approaches and tools adjusted to enhance the existing logistic process. This paper will evaluate the implementation of LSS methodology on warehousing processes in the Global FMCG Supply Chain. The key goal is to analyze the LSS impact on internal and Third Party Logistics (3P) warehouses. Considering 3P warehouses, the question is how to convince this partner to join the project and then how to exploit the developed improvement. What are the possibilities to share the experience and knowledge within the whole Global Supply Chain?

Considering the questions and goals of the research project, the research methodology chosen is the Case Study. The paper describes the practical implementation of the LSS project in the warehouse processes of an internal and 3P warehouse.

\section{Literature review}

This section defines separate methods Lean Management and Six Sigma, and a holistic approach of LSS. At the end of this section, the role of logistics in SC and LSS implementation possibilities will be described.

\subsection{Lean Management}

Lean Management is one of the most common and widely known methods of industry management. It is also known as Lean Manufacturing or Lean Production or just Lean (Bogacz \& Migza, 2016). The concept of Lean Management has its origin in the Toyota Production System (TPS). TPS contains manufacturing techniques and tools developed by Taiichi Ohno and associates soon after the Second World War. A need for a shortage of resources and capital drove it. The owner of Toyota Motor Company Eiji Toyoda instructed his workers to eliminate all waste (Pepper \& Spedding, 2010).

The goal of Lean Management is to improve the efficiency of industrial organizations. There are two main instructions: eliminate every waste in every process and place humans in the center of the process, to take advantage of their effectiveness (Sousa, et al., 2013).

Waste is defined as "anything other than the minimum amount of equipment, materials, parts, space, and time essential to add value to the product" (Russell \& Taylor, 2000). Within the process you may find eight types of waste: overproduction, waiting, 
transportation, processing, inventories, moving, defects, behaviors/skills (Emiliani \& Stec, 2004), (Harry, et al., 2010).

Together with waste elimination, Lean Management focuses on value adding operations. Added value is a value for which the client is willing to pay. Analyzing processes three types of work can be identified:

1. VA (value added) - operations increasing product or service value, the client expects and accepts it, for example, quality control.

2. BVA (business value added) - operations not increasing the value of product or service but are necessary in the current process, for example, maintenance.

3. NVA (not-value added) - redundant operations, which must be eliminated, for example, waiting for a battery change (Hamrol, 2018).

Summarizing, Lean is the most effective usage of organizational resources - make more with fewer resources (Abdi, et al., 2006).

\subsection{Six Sigma}

The Six Sigma methodology was developed in the 1980s by engineer Bill Smith at Motorola company (Snee, 2010). This approach concentrates on problem-solving. Six Sigma tools are designed to improve processes and products. Its goal is to reduce the number of defects and events. Six Sigma technical goal is to minimize the variation of the process so there will be no more than 3 defects per million parts (Brussee, 2012). Six Sigma's goal is to reach perfection in each company's process (Narula \& Grover, 2015) to deliver organizational excellence and competitive advantage on the market (Chakrabarty \& Tan, 2007).

The Six Sigma to solve problems uses the DMAIC approach: Define, Measure, Analyze, Improve, Control. The DMAIC method concentrates on specific tools and techniques.

1. Define: this step identifies customers with their requirements, and core business processes.

2. Measure: this step measures and collects data regarding current process performance.

3. Analyze: this step identifies the difference between the current and desired process, this comparison shows defects in the current process.

4. Improve: this step implements solutions to remove identified defects.

5. Control: implemented changes are controlled, so the improvement is at its best (Jayaram, 2016) (Vlasov, 2018).

\subsection{Lean Six Sigma}

Development of continuous improvement methodologies Lean Management and Six Sigma that gives strengths of both is its combination: Lean Six Sigma. LSS uses tools and philosophies from both to improve quality, reduce process variation and eliminate not-value adding activities (Salah, et al., 2011). 
Salah et al. describe LSS as a "methodology that focuses on the elimination of waste and variation, following the DMAIC structure, to achieve customer satisfaction regarding quality, delivery, and cost. The LSS focuses on improving processes, satisfying customers, and achieving a better financial result for the business" (Salah, et al., 2010).

Lean Management and Six Sigma are complementary. Six Sigma is driven by Lean giving better results than Lean and Six Sigma separately (Bhuiyan \& Baghel, 2005). A combination of these two methodologies provides the project team with a complex set of tools. These tools improve the speed and quality of each process inside the organization, giving higher profits, lower costs, and better cooperation (Bogacz \& Migza, 2016). LSS project as a combination uses some Six Sigma tools or Lean Management tools or a mix of those, depending on what is suitable for the project (Salah, et al., 2011). Figure 1 presents some examples of Six Sigma, Lean Management, and shared tools.

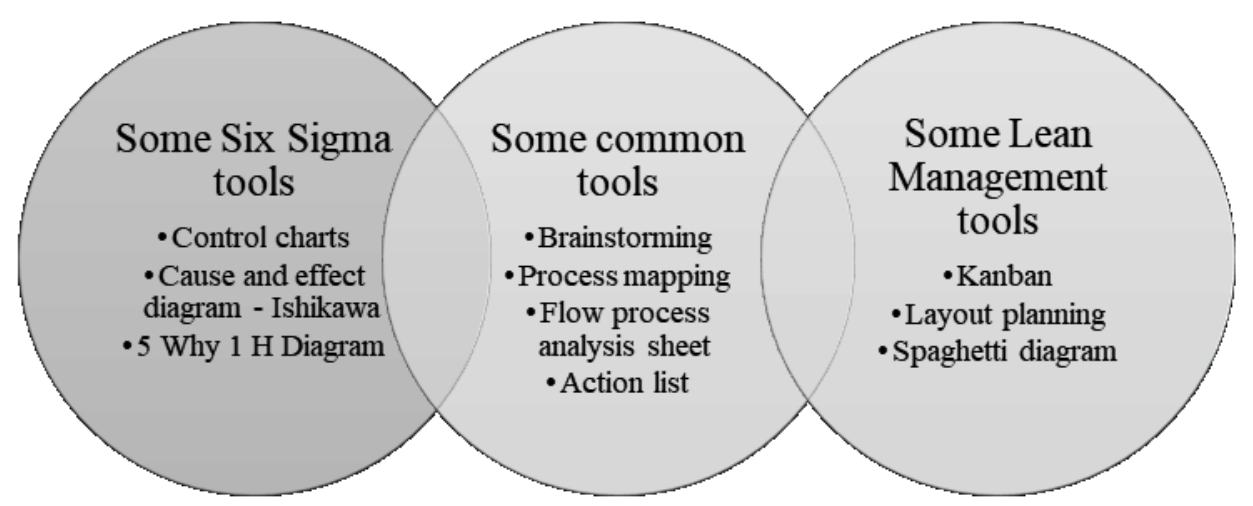

Figure 1. Examples of Six Sigma, Lean Management, and common tools. Adapted from: (Salah, et al., 2010) and (Hamrol, 2018).

\subsection{LSS in Global Supply Chain's logistics}

A Global Supply Chain (GSC) involves suppliers, manufacturers, distributors, retailers, and customers. A GSC is a very complicated type of SC as it has parties in different regions, demographics, currency, economic policies, and taxation laws. When all the parties execute responsibilities in a harmonized approach, an effective GSC is established. Each of the parties of a GSC can be in different geographical locations (Jayaram, 2016).

Organizations "plan, evaluate, improve and optimize their SCs as it helps the enterprise to grow over a period of time". Effective managing of SC leads to costs reduction, faster deliveries, and higher customer satisfaction (Jayaram, 2016). Effective and efficient management of SC leads to achieving a competitive advantage (Rahman, 2006). An efficient and effective SC can be achieved by quality control (Jayaram, 2016). Therefore, managers must develop skills in quality tools, with a focus on continuous improvement. Quality improvements should be applied regularly, mostly in main logistics functions: transport, warehousing, and inventory control (Rahman, 2006). Considering the aforementioned, it is crucial to provide 
a precise overview of logistics performance. Logistics services are the perfect area to apply LSS and continuous improvement programs (Gutierrez, et al., 2016).

\section{Case Study}

This case study concentrates on an organization that produces consumer goods. The company is a manufacturer in GSC, which produces and sells products of over 400 brands in more than 190 countries. This company produces among other foods, home, and personal care products, ice-creams, and beverages. The name of the company, position names, and program names are not disclosed for confidentiality purposes.

The company implemented sub-organizations called the operation center to handle logistics, financial, master data, and purchasing operations. There are one or more locations to handle one continent. In Europe, the company's operation center is in Poland.

A few of the operations handled by the Polish operation center are:

- transport organization from suppliers to production sites, from production sites to DC, from DCs to retailers warehouses,

- control over regional warehouses and DCs,

- implementation of improvement processes and programs, among others LSS programs.

Within the company, the LSS project was developed in Europe's operation center. The company decided to start the implementation of the LSS program with warehousing processes mostly in DCs, but also in production unit warehouses. For LSS implementation within the operation center responsible unit is "LSS champion".

\subsection{LSS Project timeline, scheme, team, tools}

The company assumes that the LSS project should be conducted in each DC and some production unit warehouses. The order of locations depends on current processes' quality, costs level, upcoming agreement renewal with the 3P DC, and others. This decision is made by the logistic manager responsible for the geographical region. It is important to plan the improvement schedule with priority on the most critical matters, but without an end - it is a continuous plan.

When the location is chosen, the timeline in Figure 2 is applied. For the LSS project, the company shares its knowledge and team: LSS champion and logistic manager. From investigating location local site management team is required and during the workshop, some employees are needed. The local site management team must be aware of warehouse processes. 


\begin{tabular}{|c|c|}
\hline eeks & $\begin{array}{l}\text { - Tasks: Introduction meeting on LSS concept with local site management } \\
\text { - Team: LSS Champion, Logistic manager, local site management }\end{array}$ \\
\hline & $\begin{array}{l}\text { - Tasks: Preparation of major Key Performance Indicators and the site's layout } \\
\text { - Team: Local site management }\end{array}$ \\
\hline & $\begin{array}{l}\text { - Tasks: Customize the workshop material and decide which process to investigat } \\
\text { - Team: LSS champion }\end{array}$ \\
\hline & $\begin{array}{l}\text { - Tasks: Creation/ update of the process map } \\
\text { - Team: Local site management }\end{array}$ \\
\hline Week 0 & $\begin{array}{l}\text { - Tasks: On-site LSS workshop } \\
\text { - Team: LSS Champion, Logistic manager, local site management, warehouse } \\
\text { employees }\end{array}$ \\
\hline & $\begin{array}{l}\text { - Tasks: Create an Action list } \\
\text { - Team: LSS Champion, Logistic manager, local site management }\end{array}$ \\
\hline & $\begin{array}{l}\text { - Tasks: Implementation of agreed actions and weekly call to check the progress } \\
\text { - Team: LSS Champion, Logistic manager, local site management }\end{array}$ \\
\hline & $\begin{array}{l}\text { - Tasks: Review call to track the progress and the benefits of the workshop } \\
\text { - Team: LSS Champion, Logistic manager, local site management }\end{array}$ \\
\hline
\end{tabular}

Figure 2. The LSS project timeline. Source: own creation based on own experience.

When the data and proper information is prepared, the two-days workshop is conducted. The company adjusted the DMAIC approach for their own LSS project purpose and change it to Analysis, Identification, Design, Implementation. LSS project is continuous improvement so these steps will repeat regularly, Figure 3.

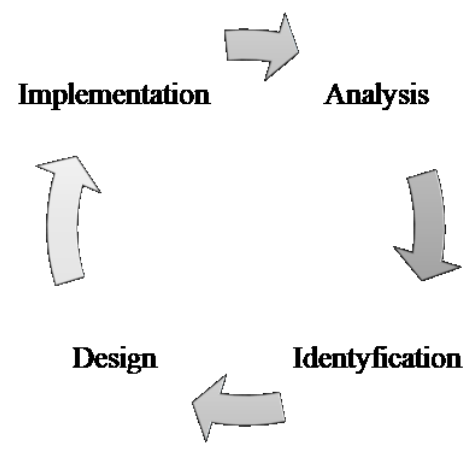

Figure 3. LSS continuous cycle. Source: own creation based on own experience.

Each of these steps plays an important role in the LSS project, and is adapted with LSS tools. 


\subsection{Analysis phase}

The Analysis phase describes the characteristics of the warehouse, process steps, improvement opportunities, and what is happening on the floor. This phase uses two LSS tools: process map and cause-and-effect diagram.

"A process map is a graphical representation that shows a sequence of activities/steps represented by flowchart symbols". It shows a visual description of the process (Harry, et al., 2010). The visual aspect helps in the process's understanding, and it's important to review the process map at this step of the LSS cycle. Example presented in Figure 4.

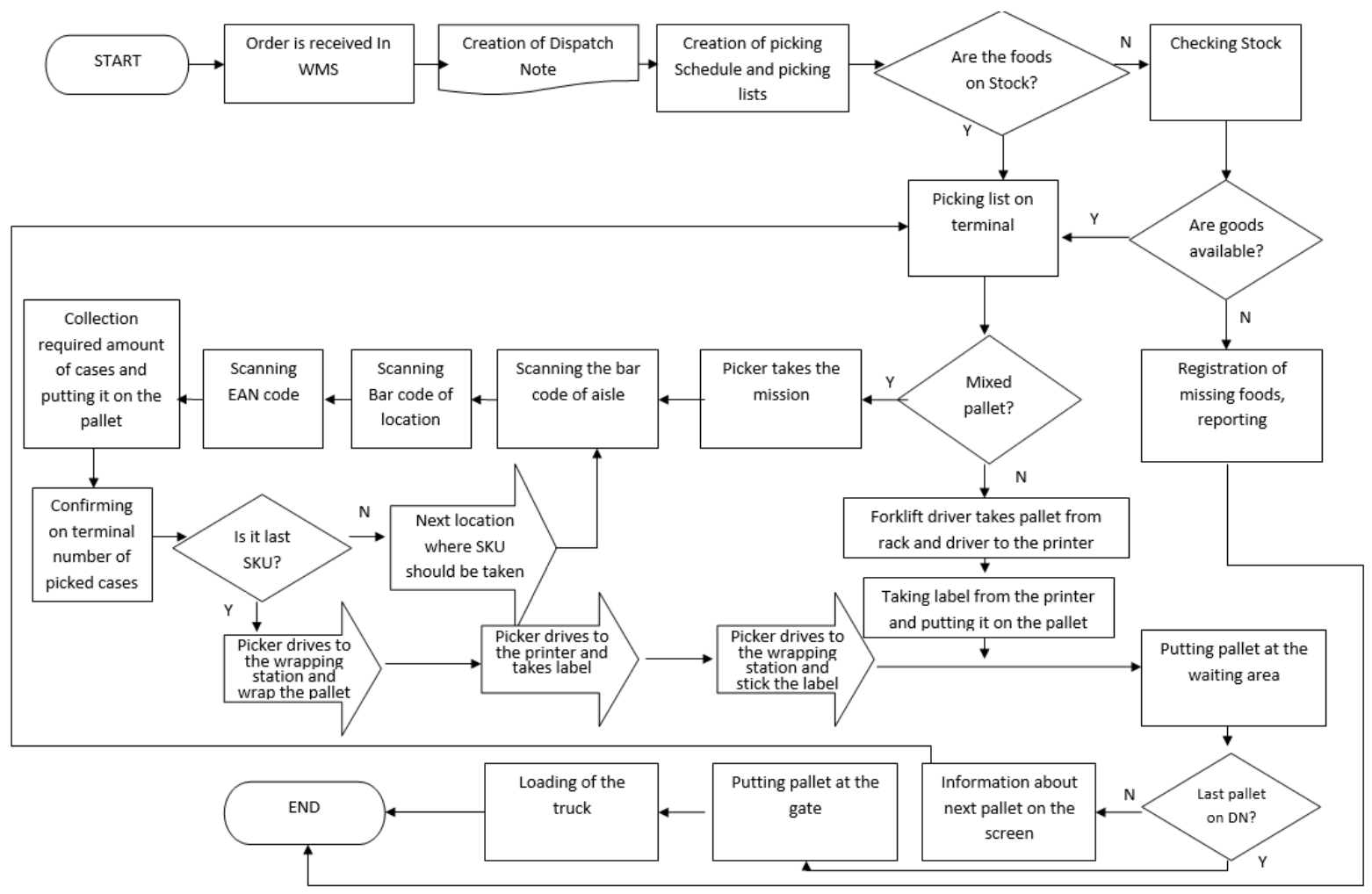

Figure 4. Process map example. Source: own work based on own experience.

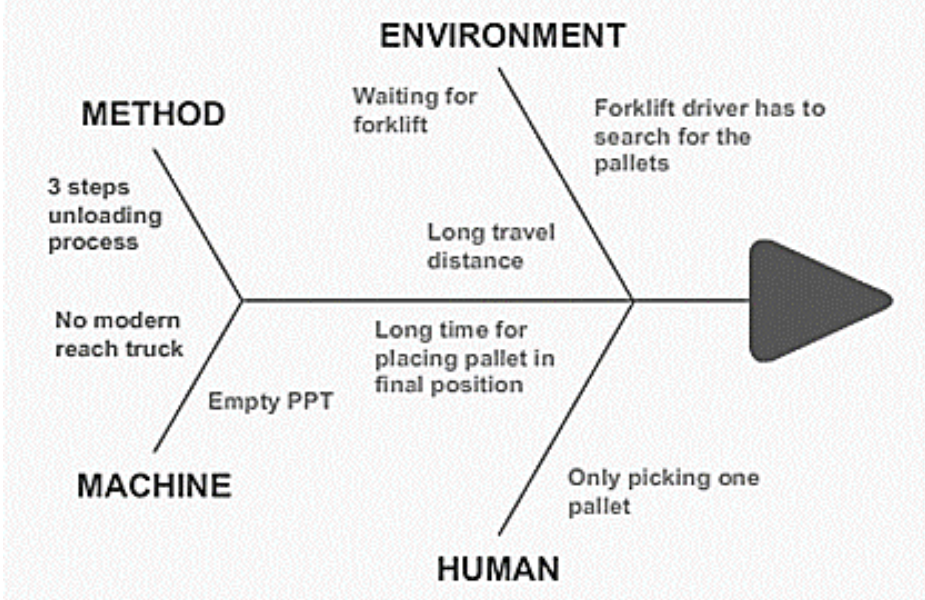

Figure 5. Cause-and-effect diagram example. Source: own work based on own experience. 
The cause-and-effect diagram is also known as the Ishikawa diagram or the Fishbone diagram. A cause-and-effect diagram is an analysis tool that proposes a systematic way of seeing effects and the causes that create those effects. The shape of the diagram leads LSS team members to think systematically. This diagram helps to identify the root causes of a problem using a structured method, encourages group involvement, and uses group knowledge of the process, identifies areas where data should be collected for more detailed analysis (Ciocoiu \& Ilie, 2010). The diagram example is shown in Figure 5.

\subsection{Identification phase}

The Identification phase is an important step when the LSS team goes to the warehouse and observes the process steps on the floor in real-time. This phase shows the real material flow and points inefficiencies, in particular wastes. The LSS team uses a flow process analysis sheet, travel-and-material flow diagram, and 5Why\&1How analysis in this step. All workshop members go to the warehouse where the diagnosed process is running. The team needs to have an empty flow process analysis sheet, printed layout of the warehouse, and a stopwatch. Then the team follows one ware-house employee at a time who executes the process, for example, a picker who collects an order. Detailed data must be noted: time spends on each operation, the distance between each operation, type of operation, the value of the operation, and comments, for example, see Figure 6.

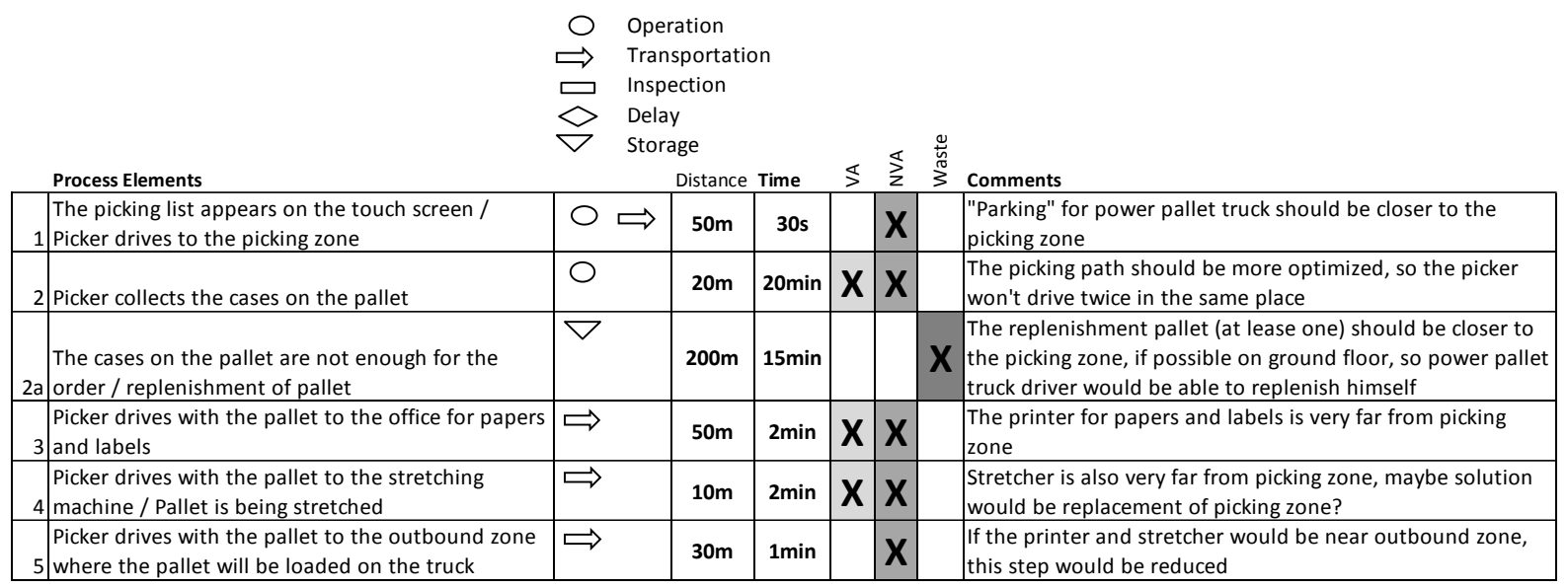

Figure 6. Flow process analysis sheet example. Source: own work based on own experience.

At the same time another LSS team member draws lines with marking operations number on the warehouse layout - this way they will create a travel-and-material flow diagram, also called the Spaghetti diagram. The example is presented in Figure 7. These two steps should be repeated a few times, as inefficiencies may appear randomly. 


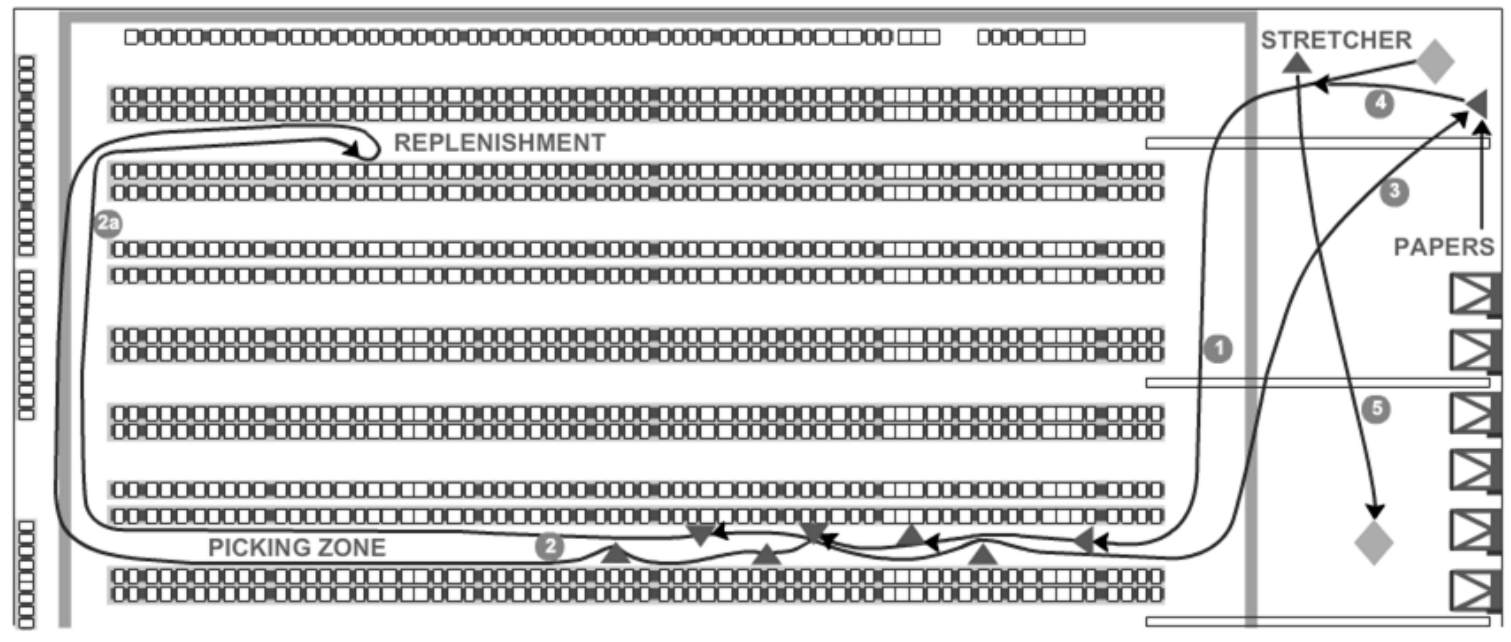

Figure 7. Spaghetti diagram example. Source: own work based on own experience.

When real-time process observation is finished, the team analyzes wastes with 5Why\&1How analysis, see example in Figure 8. 5Why\&1How analysis helps to identify the root cause and range of the problem. Such detailed information benefits in finding the right problem solution.

\begin{tabular}{|c|c|c|c|c|}
\hline & Timeframe & $30 \mathrm{~min}$ & $\begin{array}{l}\text { Spadict } \\
\text { Chronic }\end{array}$ & C \\
\hline & Question & Comments & & \\
\hline $\mathbf{W}$ & $\begin{array}{l}\text { What: In which process step a problem } \\
\text { is seen? }\end{array}$ & \multicolumn{3}{|l|}{$\begin{array}{l}\text { The problem is seen at the } 2 \text { nd step of the picking } \\
\text { process }\end{array}$} \\
\hline $\mathbf{W}$ & $\begin{array}{l}\text { When: When was the problem } \\
\text { detected? }\end{array}$ & \multicolumn{3}{|l|}{ After 5 th pallet } \\
\hline $\mathbf{W}$ & $\begin{array}{l}\text { Where: At which place happened the } \\
\text { problem? }\end{array}$ & \multicolumn{3}{|l|}{ In the picking zone to replenishment zone } \\
\hline $\mathbf{W}$ & $\begin{array}{l}\text { Who: Has the problem to do with } \\
\text { personnel capability? }\end{array}$ & \multicolumn{3}{|l|}{ No, it is connected to the method } \\
\hline $\mathbf{W}$ & $\begin{array}{l}\text { Which: Do you see a trend in this } \\
\text { problem? }\end{array}$ & \multicolumn{3}{|l|}{ No, it is the constant problem } \\
\hline $\mathbf{H}$ & $\begin{array}{l}\text { How: How far is the process from the } \\
\text { standard process? }\end{array}$ & \multicolumn{3}{|c|}{ It is very far from the standard process, replenishment should take max. $3 \mathrm{~min}$. } \\
\hline
\end{tabular}

Figure 8. 5Why\&1How analysis example. Source: own work based on own experience.

\subsection{Design phase}

The Design phase determines the changes in the process. To eliminate wastes, solutions are created and presented in a new process map. This phase uses the ECRS tool and an Action list. 


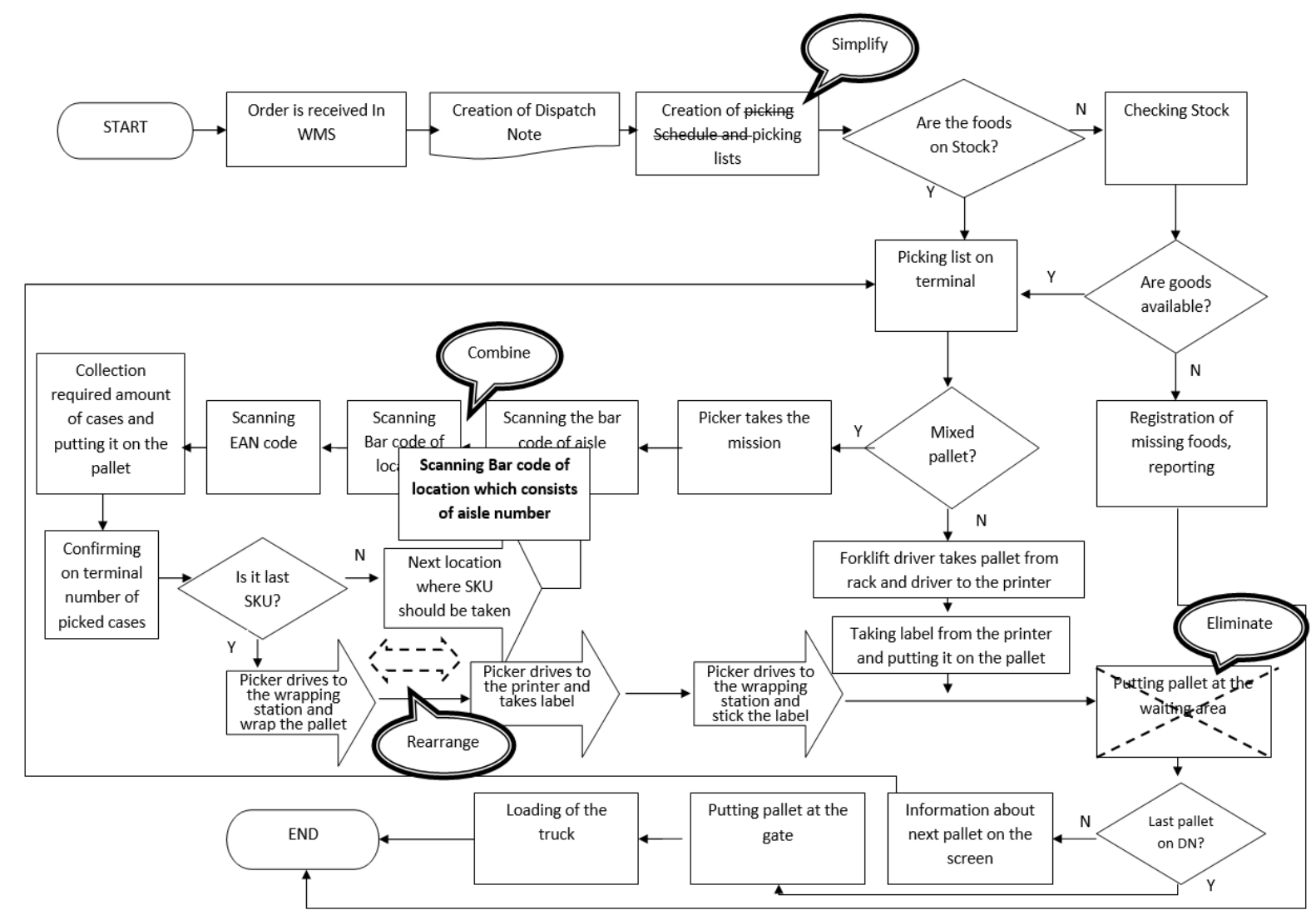

Figure 9. ECRS tool example. Source: own work based on own experience.

The ECRS tool helps to find improvements in the process map. ECRS includes 4 steps: Eliminate, Combine, Rearrange, Simplify. First, eliminate unnecessary operations, then combine different operations in the process, next rearrange the sequence of different operations, and at last simplify current process' operations. The example presented in Figure 9 corresponds with the process map from Figure 4.

All the changes designed during the workshop are presented in the Action list tool. The Action list contains the type of the process, list of changes to be implemented, responsible persons, date when the solution was raised, date when implementation should be finished. Making the Action list is critical, as it is proof of the workshop efficiency and shows who is the responsible party. At last, it helps in the Implementation phase. The action list with examples of designed actions is shown in Figure 10. 


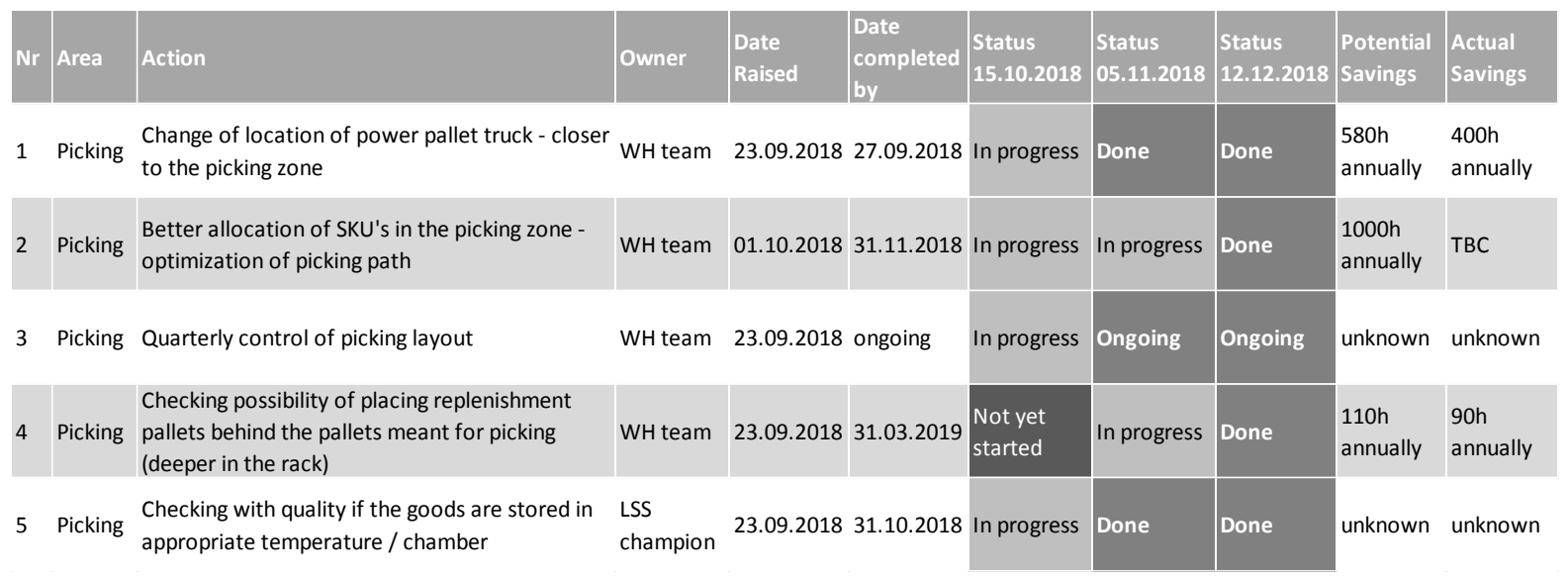

Figure 10. Action list example. Source: own work based on own experience.

\subsection{Implementation phase}

In the Implementation phase, parties execute tasks agreed during the workshop and stated in the Action list. That is the one stage that happens after the workshop. During the Implementation phase, the LSS team is running regular - weekly/monthly calls to check the status of listed actions. In this phase, what is critical potential and actual saving is calculated.

When this phase is finished, the LSS team prepares for the next workshop, to investigate another process or another warehouse.

\subsection{LSS project results in an internal distribution center}

By this time the company has conducted many LSS workshops across Europe and more. One of the workshops concentrated on the picking process in German oil and fats DC. This DC is loading ca. 11000 trucks with over 270k full pallets and more than 30k mixed pallets each year. It has a capability of over $17 \mathrm{k}$ pallet spaces. It is an internal DC, owned by the company. Any improvement change brings actual and direct savings to the company. Cooperation with the internal DC is smooth, as the entire LSS team belongs to the company.

During the workshop, many inefficiencies were recognized. Among other below changes were implemented:

- change the picking zone location,

- pallets machine automatization,

- upgrade of the picking trucks to the new ones,

- change the location of empty pallets,

- reduce the number of printed labels,

- upgrade of the stretching equipment.

Foregoing changes brought the saving of 130k EUR per annum delivered directly to the company's wallet. 


\subsection{LSS project results in a 3P distribution center}

Another two workshops organized by the European LSS champion took place in a 3P warehouse in Austria. Firstly the picking process was investigated, secondly the handling process was examined. This DC handles a wide range of foods, both controlled and ambient temperature, as well as home and personal care products. This location handles almost $360 \mathrm{k}$ pallets, with incoming $3 \mathrm{k}$ trucks and outgoing ca. $7,5 \mathrm{k}$ trucks yearly. It has a capacity of $27,5 \mathrm{k}$ pallet spaces. Taking into consideration it is a 3rd Party Logistics warehouse, some difficulties were met. In the beginning, the LSS champion and the logistics manager had to convince the site managers about the benefits of the project. During the workshop the team faced resistance from warehouse floor employees, they were afraid of losing their position when inefficient. Last, of all, the company was concerned about how saving can be gained from the 3P provider.

Both workshops revealed many non-value adding operations and wastes. Some implemented changes:

- replenishment when minimum stock is 3 cases,

- change start location for picking process,

- mixing temperature-controlled goods with temperature neutral goods on one pallet,

- increased number of printers in the warehouse,

- started dock booking function,

- decreased number of empty runs - taxi driver must always drive with 2 pallets.

The implemented changes released the saving of $0,8 \mathrm{~m}$ EUR yearly. It also allowed an increasing number of stored pallets to 6000 pallets more. Because of agreement renewal, the company negotiated services price reduction. These finally brought the company's savings of almost $2 \mathrm{~m}$ EUR.

\section{Discussion and conclusions}

The LSS method benefits from a combination of two effective continuous improvement methodologies. The LSS can and should be adapted to a company's requirements. The approach and set of tools fit an organization's needs.

The paper presents how the LSS can make logistic processes better and this way improves customer satisfaction.

The LSS project within the company was tailored and a special scheme was created. The company adjusted the DMAIC method and introduced four steps, Identification, Analysis, Design, and Implementation. The LSS team uses many adapted tools to find areas of improvement. 
The case study shows that in both examined DCs inefficiencies have been found. While in internal DC the project was carried out with simplicity, the 3P DC caused difficulties. Saving was presented immediately in internal DC, but in 3P DC the company collected benefits from improvements only when a new agreement was signed.

In general, the paper shows that the company is satisfied with the LSS project results. The company extends the range of the LSS project to other continents. At the same time, the European LSS champion shares the know-how and the LSS project scheme with all the company's co-workers by Learning Management System training. Considering the current situation when many office employees work from home, future research may focus on the results of running the LSS project remotely, through online meetings and workshops.

\section{References}

1. Abdi, F., Shavarini, S. \& Hoseini, S. (2006). Glean lean: How to use lean approach in services industries? Journal of Services Research. 6., pp. 191-206.

2. Bhuiyan, N. \& Baghel, A. (2005). An overview of continuous improvement: from the past to the present. Management Decision, 43(5), pp. 761-771.

3. Bogacz, P. \& Migza, M. (2016). Zastosowanie Lean Six Sigma w doskonaleniu procesów produkcyjnych w przemyśle wydobywczym [Application of Lean Six Sigma in Production Processes Improvement in Extractive Industry]. Inżynieria Mineralna, Lipiec-Grudzień, pp. 23-29.

4. Brussee, W. (2012). Statistics for Six Sigma Made Easy! Revised and Expanded Second Edition. McGraw-Hill Education.

5. Chakrabarty, A. \& Tan, K. (2007). The current state of six sigma application in services. Managing Service Quality, 17(2), pp. 194-208.

6. Ciocoiu, C. \& Ilie, G. (2010). Application Of Fishbone Diagram To Determine The Risk Of An Event With Multiple Causes. Management Research and Practice, Tom 2, pp. 1-20.

7. Emiliani, M. \& Stec, D. (2004). Using value-stream maps to improve leadership. Leadership \& Organization Development Journal, Tom 25, pp. 622-645.

8. Gupta, V., Jain, R. \& Meena, M. (2018). Six-sigma application in tire-manufacturing company: a case study. J. Ind. Eng. Int., Tom 14, pp. 511-520.

9. Gutierrez, L., De Leeuw, S. \& Dubbers, R. (2016). Logistics services and Lean Six Sigma implementation: a case study. International Journal of Lean Six Sigma, 7(3), pp. 324-342.

10. Hamrol, A. (2018). Strategie i praktyki sprawnego działania. Lean, Six Sigma i inne. [Strategies and practises of efficient action. Lean Six Sigma and others]. Warszawa: PWN.

11. Harry, M. \& others (2010). The practitioner's guide to statistics and lean Six Sigma for process improvements. Hoboken, NJ: John Wiley \& Sons, Inc. 
12. Jayaram, A. (2016). Lean Six Sigma Approach for Global Supply Chain Management using Industry 4.0 and IIoT. Noida, pp. 89-94.

13. Narula, V. \& Grover, S. (2015). Six Sigma: literature Review and Implications for future research. Int J Ind Eng, 26(1), pp. 13-26.

14. Pepper, M. \& Spedding, T. (2010). The evolution of lean Six Sigma. International Journal of Quality \& Reliability Management, 27(2), pp. 138-155.

15. Rahman, S. (2006). Quality management in Logistics: an examination of industry practices. Supply chain Management: An International Journal, 11(3), pp. 233-240.

16. Russell, R. \& Taylor, B. (2000). Operations Management. Englewood Cliffs, NJ: PrenticeHall.

17. Salah, S., Rahim, A. \& Carretero, J. (2010). The integration of Six Sigma and lean management. International Journal of Lean Six Sigma, Tom 1, pp. 249-274.

18. Salah, S., Rahim, A. \& Carretero, J. (2011). Implementation of Lean Six Sigma (LSS) in supply chain management (SCM): an integrated management philosophy. Int. J. Transitions and Innovation Systems, 1(2), pp. 138-162.

19. Snee, R. (2010). Lean Six Sigma - getting better all the time. International Journal of Lean Six Sigma, Tom 1, pp. 9-29.

20. Sousa, S., Antunes, D. \& Nunes, E. (2013). Using project Six Sigma and Lean concepts in internal logistics. Lecture Notes in Engineering and Computer Science, Tom 1.

21. Vlasov, V. (2018). Increasing the implementation capability of Lean Six Sigma through the integration with a learning organisation concept. Zarzadzanie Przedsiębiorstwem. Enterprise Management, 21(4), pp. 30-36. 